\title{
Implementation and Evaluation of Management Guidelines for Atopic Eczema for Primary Health Care Nurses: A Pilot Study
}

\author{
Kaarina F Meintjes ${ }^{1}$ \\ ${ }^{1}$ Nursing Department, University of Johannesburg, Johannesburg, South Africa \\ Correspondence: Kaarina Meintjes, Nursing Department, University of Johannesburg, Johannesburg, South Africa. \\ Tel: 27-11-559-6984. E-mail: kaarinam@uj.ac.za
}

Received: September 19, 2019 Accepted: October 28, 2019 Online Published: April 7, 2020

doi:10.5539/gjhs.v12n6p1 URL: https://doi.org/10.5539/gjhs.v12n6p1

\begin{abstract}
The primary health care (PHC) management guidelines for nurses treating children with atopic eczema were developed in a baseline study. The purpose of this study was to implement and evaluate the guidelines through a pilot study in a district in Gauteng, South Africa, in order to identify challenges and to adopt or adjust the guidelines for use by primary health care nurses in South Africa. The ultimate aim is to improve the child's eczema and quality of life.

A process evaluation research design was followed. Data was collected through 1) in-depth interviews with PHC nurses and also with the parents of children treated by these PHC nurses, and 2) documentation using the patient files of these children.

The results showed that some aspects of the guidelines were used and seen as helpful, especially the complete emollient therapy and the evidence based health education. A simplified version of the guideline will be promoted for use by PHC nurses. The more detailed guideline could possibly be used as a basis to develop a short course on atopic eczema for PHC nurses.
\end{abstract}

Keywords: Atopic eczema, management guidelines, primary health care nurse

\section{Introduction}

A baseline research study was done on the PHC management of childhood atopic eczema (AE) public health care domain in South Africa. The central theme emerged: Childhood AE had a physical, emotional and social effect on all parties involved and the chronic nature and the lack of effective management caused high levels of frustration for the parents, doctors and PHC nurses. Many PHC management challenges were identified, namely ineffective or insufficient quantities of drug management and limited treatment protocols; assessment challenges; inadequate health education provided; inadequate knowledge levels of PHC nurses; ineffective referral systems; and financial challenges for both the parents as well as government. Based on the findings of this baseline research, primary health care (PHC) management guidelines for childhood AE were developed and validated (Meintjes, 2016) following the AGREE II Instrument (Brouwers et al., 2010). These PHC management guidelines for childhood AE (hereafter called the guidelines) have been implemented and evaluated in a pilot study in the PHC clinical setting and the findings are reported in this article.

\subsection{Aims and Objectives}

The aim was to implement the guidelines in PHC clinics through a pilot study and to evaluate the implementation thereof, in order to identify challenges and to adopt or adjust the guideline for use by primary health care nurses in South Africa. The ultimate aim is to improve the child's eczema and quality of life.

The objectives were:

- To train PHC nurses in all aspects of AE contained in the guidelines.

- To explore the use of the guidelines by the trained PHC nurses and the effect thereof on the children with AE.

- $\quad$ Based on the findings to adopt or modify the guidelines.

\section{Research Methodology}

A process evaluation research design was followed. Process evaluation research focuses on the gathering of 
information needed to adopt, modify or abandon a program, procedure or policy and usually uses both quantitative and qualitative data collection methods (Polit \& Beck, 2012). Process evaluation with a convergent mixed method design was used for this pilot study on the implementation and evaluation of the guidelines in PHC clinics a sub-district of the central district of Gauteng. Trustworthiness was ensured following the Guba model (Lincoln \& Guba, 1985). Credibility was ensured through prolonged engagement by spending time with the participants and with the data during analysis; field notes that improved the accuracy of the collected data; triangulation of sources for data collection; and using Tesch's widely recognized eight steps of descriptive data analysis. Transferability was done through a dense description of the research methodology and results; direct quotations from the participant and triangulation of data sources. Dependability was also done though detailed description of the research methodology. Confirmability was done by applying bracketing and reflexive thinking throughout data collection and analysis as well as keeping documents for the audit trail.

A summary is provided in Table I. Ethical principles namely autonomy, beneficence, non-maleficence and justice was applied throughout the study (Dhai \& McQuoid-Mason, 2011). Ethical clearance was obtained from the University of Johannesburg as well as the Gauteng Department of Health.

\subsection{Population and Sampling}

The population for this study was all the PHC nurses working in the 11 PHC clinics in a sub-district of the central district of Gauteng; as well as the parents with a child with atopic eczema who attended one of these clinics. These PHC clinics included both local authority and provincial facilities (GHOD, n.d). A different sub-district and clinics were identified for this pilot study than what was used in the baseline study, in order to prevent bias and contamination. Purposive sampling was used to collect data. The inclusion criteria were:

- $\quad$ The PHC nurse who:

- Holds the qualification: Clinical assessment, diagnosis, treatment and care (South African Nursing Council (SANC), Regulation 48).

- Attended the in-service training session on $\mathrm{AE}$ and the PHC management guidelines and

- Gave consent to participate in the research.

- The parents of children with AE:

- They must already have a diagnosis of AE and utilized treatment from a PHC clinic before. The reason for this is because there was no verification for the accuracy of a first time $\mathrm{AE}$ diagnosis made by the PHC nurse.

- The children were treated by PHC nurses who were trained in using the guidelines and

- Gave consent to participate in the research.

- The patient files of the abovementioned children.

The process for purposive sampling was as follows:

Permission to conduct the study was obtained from the relevant authorities. Thereafter, the research was explained to the area managers. After they gave permission for the study to be conducted in their area, two dates and times were arranged for in-service training for PHC nurses who were interested in the topic and the research. After the training, those PHC nurses who were willing to participate in the research, completed a consent letter. These PHC nurses had to collect the contact details of parents whose children with AE they treated according to the guidelines. If the parents gave permission to the PHC nurse to hand their contact details to the researcher, they were contacted and an appointment was made for an interview. The sample size for the interviews depended on data saturation.

The patient files of the children who were treated for AE by participating PHC nurses and whose parents also consented to participate in the research, were retrieved for document analysis.

\subsection{Data Collection and Analysis}

\subsubsection{Data Collection}

The research was conducted in two stages:

\section{Stage one: Preparing the PHC Nurses to Use the Guidelines}

The research was explained to the PHC nurses who attended the in-service training. Those who gave consent to participate also had to provide additional consent to be interviewed and audio-taped. All the PHC nurses who attended the training session received the information even if they did not consent to partake in the research. The 
in-service training session contained of an interactive lecture on various aspects of $\mathrm{AE}$, including what is $\mathrm{AE}$, the etiology and the outside-inside theory for AE development as well as all the elements contained in the guidelines, namely: assessment of the severity of the atopic eczema as mild, moderate or severe; complete emollient therapy; topical corticosteroid ointment; role of antihistamine in AE; relevant health education; and referral to other members of the multidisciplinary team if indicated. Two three-hour training sessions were conducted for PHC nurses from 11 clinics. Each participant received a full guideline as well as a shortened easy-to-use version, for reference when consulting the parents with children with AE.

\section{Stage two: Data Collection over a Period of 9 Months}

In-depth individual interviews: Data was collected through in-depth individual interviews with consenting PHC nurses and parents from children treated by these PHC nurses. Field notes were also kept directly after the interviews. The interviews were done 3-9 months after the PHC nurses started using the guidelines.

Interviews with the PHC nurses were done at a time and place that suited them. The interviews with the parents were done at their homes at a time that suited them. The parents all preferred the interviews at home, because it saved them transport costs. All the interviews lasted between 45-60 minutes. The interviews with six of the seven PHC nurses and all the parents were conducted in English. All the parents could speak English, although it was not their first language. One interview with a PHC nurse was conducted in Afrikaans as this was the mother tongue of the researcher and the participant. The question asked for the PHC nurses was:

"How was it for you to use the primary health care management guidelines for childhood atopic eczema?"

The question asked for the parents was:

"How was the treatment of your child's eczema?"

All the interviews were audiotaped to ensure that no valuable information got lost. Data was collected until data saturation occurs, that is until no new information was forthcoming. Data saturation for the PHC nurses occurred after 5 interviews, but all 7 consenting PHC nurses were interviewed. Data saturation for the interviews with parents occurred after 4 interviews.

Documentation: Data was furthermore collected through document analysis of the patients' files of these children who were treated by trained PHC nurses and whose parents consented to take part in the research. The number of patient files were $10(n=10)$. The items that were looked for in the patients' files were: assessment of the severity of the AE into mild, moderate or severe; prescription of $1 \% \mathrm{TCS}$; referral to the doctor for prescription of a moderate strength TCS; prescription of an emollient; amount of the emollient dispensed - at least $1 \times 700 \mathrm{~g}$ container; antihistamine prescribed; health education given; type of health education specified; referral to other members of the multi-disciplinary team. A tick list was used against the abovementioned items for each of the ten files for the relevant clinic visit regarding the $\mathrm{AE}$.

\subsection{Data Analysis}

In-depth individual interviews: All the audiotaped interviews were transcribed verbatim. The interview conducted in Afrikaans was transcribed verbatim and analysed in the original language and thereafter transcribed in English. Field notes were added to the transcribed interviews to enrich the data. The researcher and an independent coder both analysed the data of the interviews using Tesch's method of open coding, as described in Creswell (2014). A consensus discussion was held to refine and finalise the themes and categories. The themes that were identified were: complete emollient therapy is effective; topical corticosteroid use; health education; and the lack of use of the guidelines. The themes and categories are reflected in Table 1. 
Table 1 . Themes and categories of qualitative data analysis

\begin{tabular}{|c|c|}
\hline Themes & Categories \\
\hline 1. Complete emollient therapy & $\begin{array}{l}\text { - This was new information } \\
\text { - It is effective, but takes time } \\
\text { - } \quad \text { Not enough emollient therapy available to give for the } \\
\text { whole month }\end{array}$ \\
\hline 2. Topical corticosteroid & $\begin{array}{ll}\text { - } & 1 \% \text { TCS limited effect } \\
\text { - } & \text { Moderate TCS effective, but not always available } \\
\text { - } & \text { Finger-tip-unit }\end{array}$ \\
\hline 3. Health education & $\begin{array}{l}\text { - Was seen as helpful especially on: } \\
\circ \quad \text { Soft clothing } \\
\circ \quad \text { Complete emollient therapy } \\
\text { - } \quad \text { Time available for health education } \\
\text { - Compliance: } \\
\circ \quad \text { To both drug and non-drug is essential for good } \\
\text { result } \\
\circ \quad \begin{array}{l}\text { Takes time, thus both parent and PHC nurse } \\
\text { must be patient }\end{array}\end{array}$ \\
\hline 4. Lack of using guidelines & $\begin{array}{l}\text { - Determining severity of atopic eczema } \\
\text { - Some health education without using evidence based } \\
\text { guidelines }\end{array}$ \\
\hline
\end{tabular}

Document analysis: The patients' files are kept in the PHC clinics. These patient files were retrieved and analysed. Descriptive data analysis was used for the document analysis of the files of the ten $(n=10)$ patients who gave consent to partake in the research. The results are summarized in Table 2.

Table 2. Document analysis

\begin{tabular}{lll}
\hline Item checked & Frequency & Percentage \\
\hline Assessment of the severity of the atopic eczema into mild, moderate or severe & 0 & $0 \%$ \\
Prescription of emollient & 10 & $100 \%$ \\
Amount dispensed at least 1x 700g container & 10 & $100 \%$ \\
Prescription of 1\% topical corticosteroid (TCS) & 10 & $100 \%$ \\
Referral to doctor for a moderate strength TCS & 1 & $10 \%$ \\
Health education given & 10 & $100 \%$ \\
Type of health education specified & 3 & $30 \%$ \\
Referral to other members of the multi-disciplinary team (excluding the doctor) & 0 & 0 \\
Antihistamine prescribed & 1 & $10 \%$ \\
\hline
\end{tabular}

The data from both the in-depth individual interviews and the document analysis were then analysed together, using interpretative embedded data integration through joint display (Gueterman, Fetters, \& Creswell, 2015). A side-by-side joint display of both sets of data was done to get an overall picture of the results as depicted in figures $1,2,3,4$. 


\section{Joint display of qualitative and quantitative results}

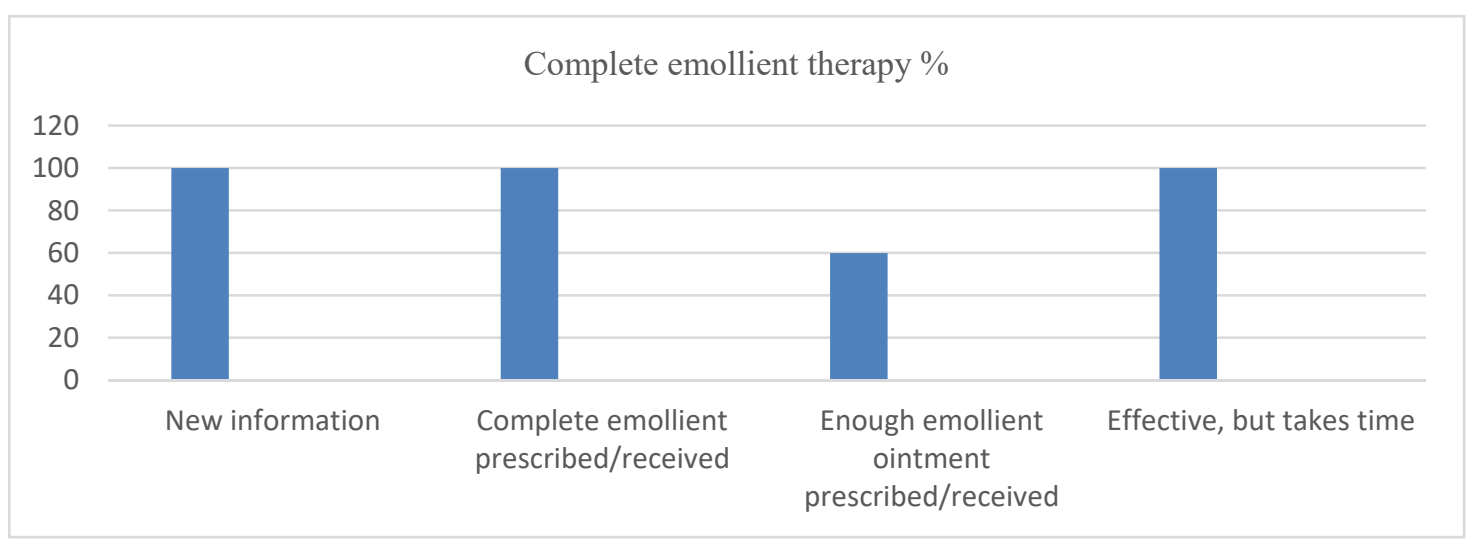

Figure 1. Complete emollient therapy

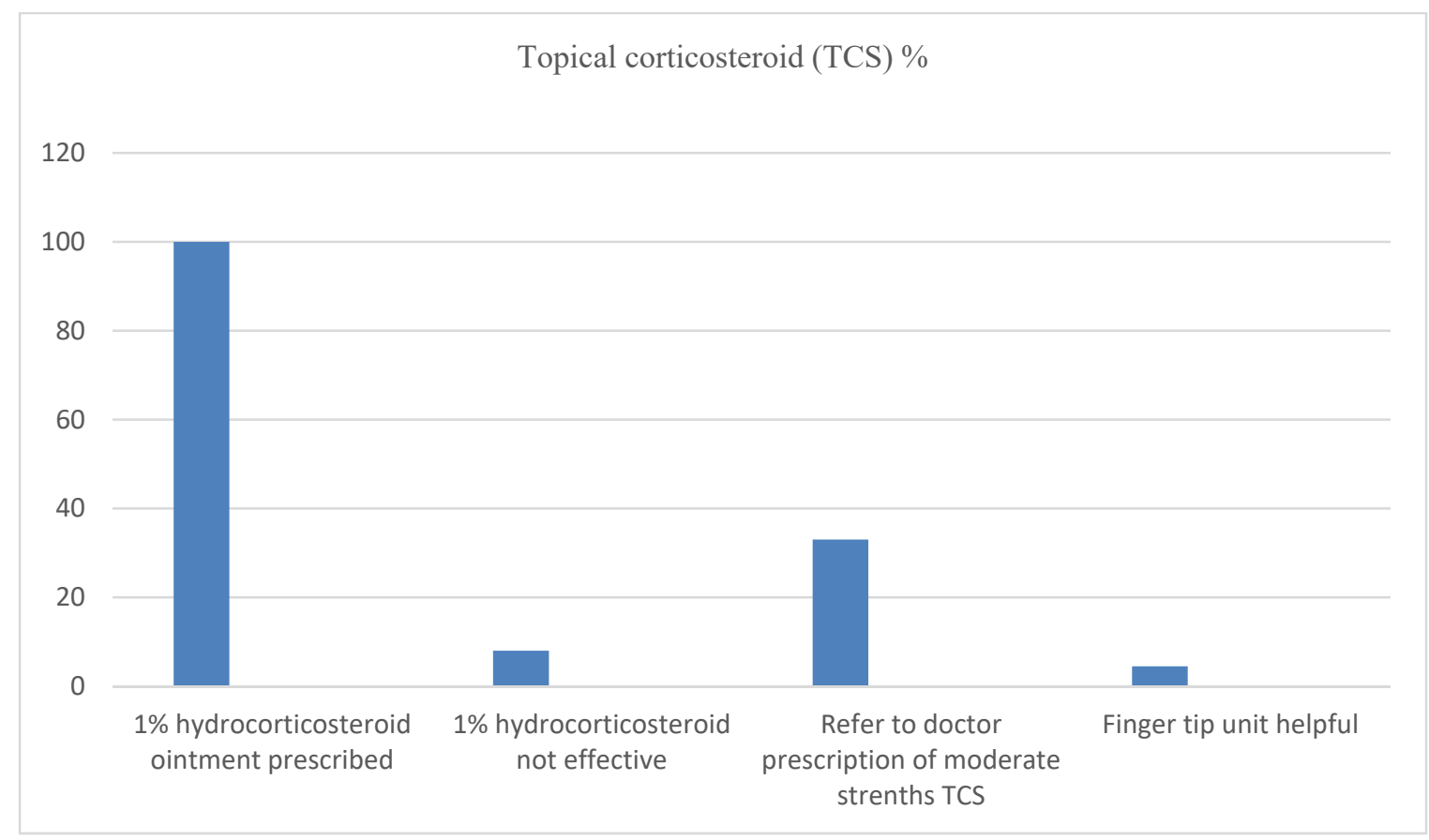

Figure 2. Topical corticosteroid 


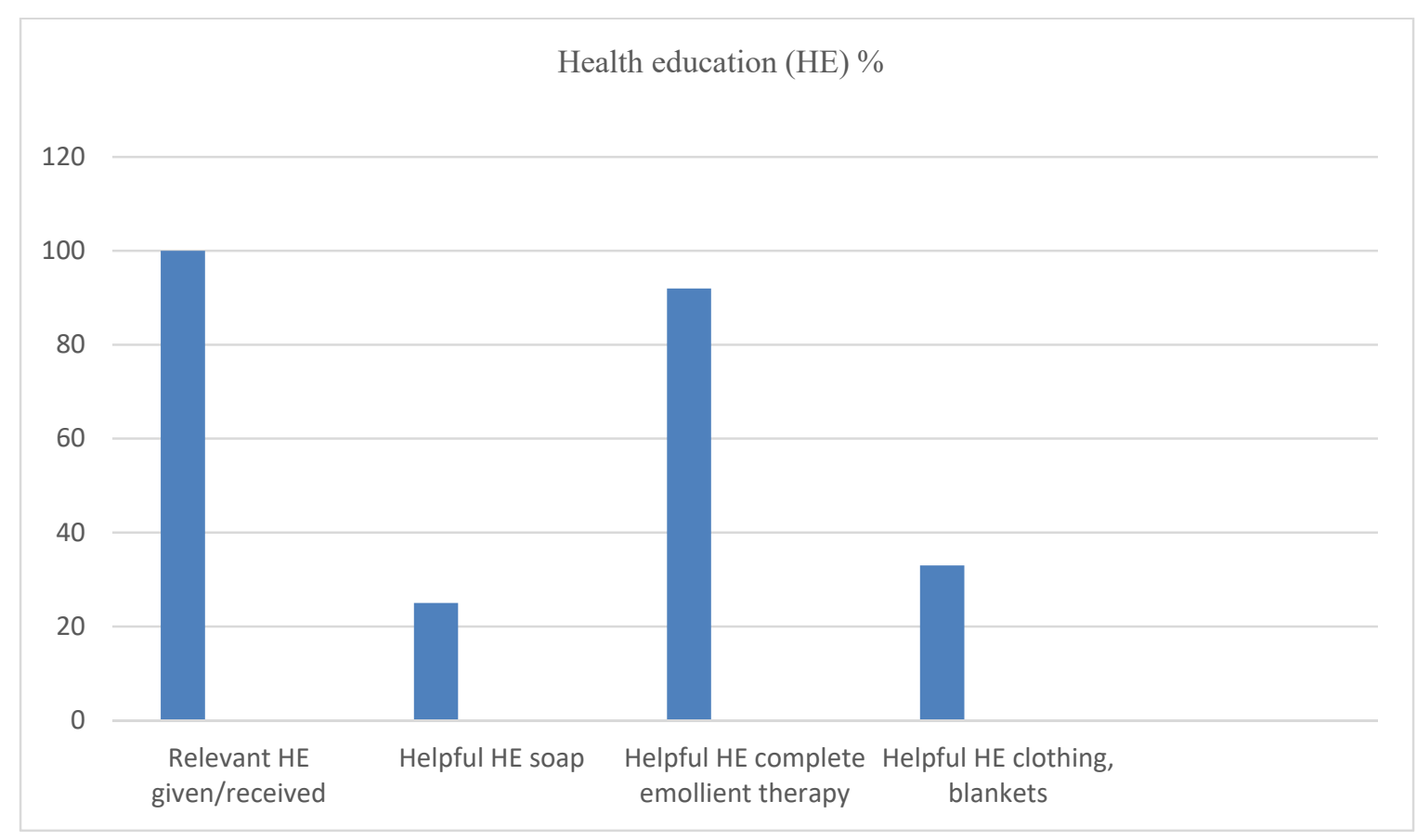

Figure 3. Health education

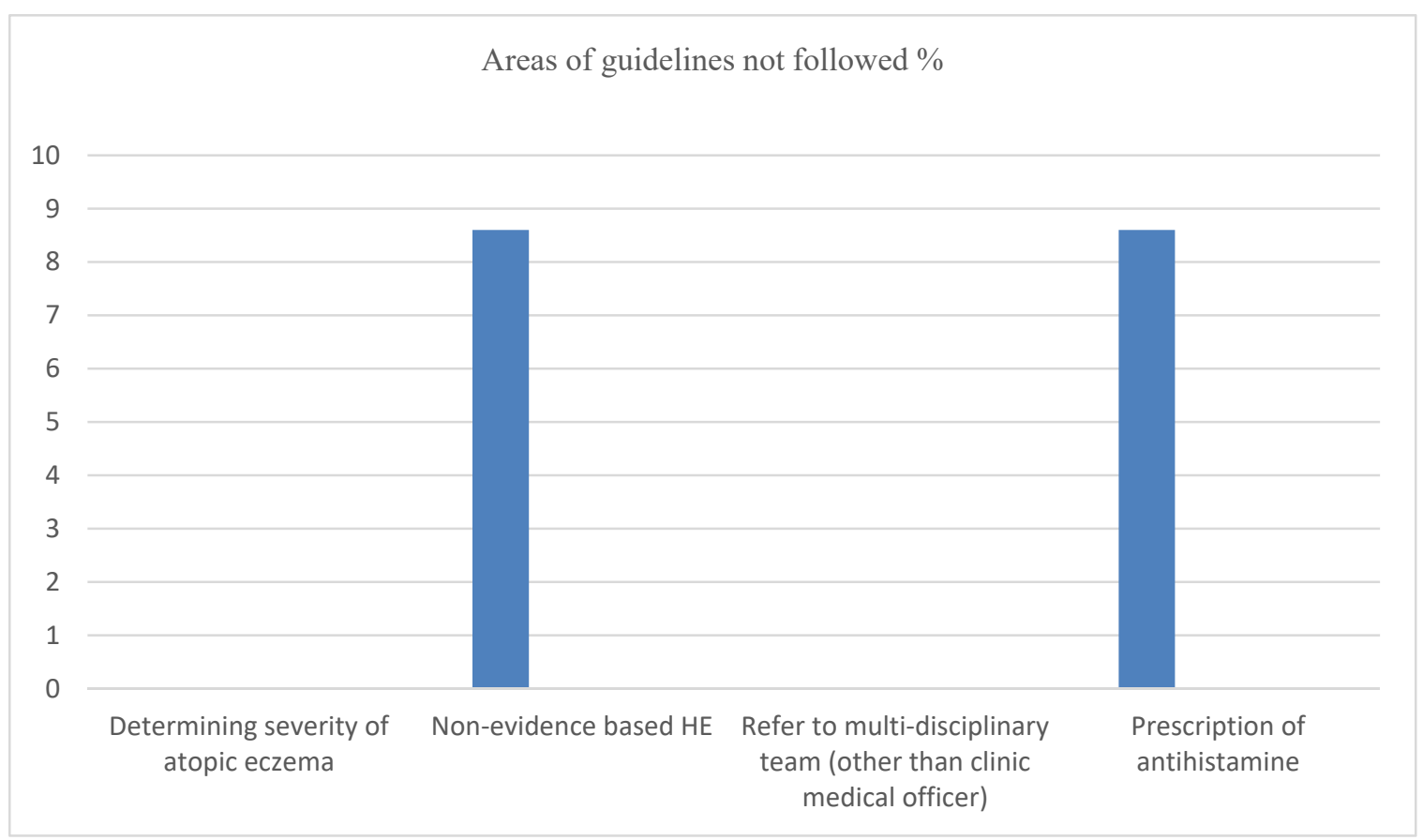

Figure 4. Areas were guidelines were not followed

\section{Discussion of findings}

\subsection{Demographic Data}

Twenty-two PHC nurses attended the training sessions and all were trained in using the guidelines. Seven (7) of these trained PHC nurses consented to partake in the research. The reason provided by those not consenting were: nine (9) were too busy in the clinics to try out something new; three (3) did not provide a reason; and three (3) were operational managers who were less often involved in patient consultations. Of the seven (7) consenting PHC nurses, two (2) were male and five (5) were female. Their years of experience as a PHC nurse ranged from 3-30 years. 
After the consenting PHC nurses used the guidelines when consulting children with atopic eczema, ten (10) parentsprovided consent to partake in the study. Even if parents did not give permission to partake in the study, they were still managed according to the guidelines. Five (5) consenting parents could not be followed up as there cell phone numbers did not take any voice message and they did not phone back. These numbers were dialed on various occasions. Of the parents who were interviewed, one was a father and the other four were mothers of a child with atopic eczema. Two (2) of these children were females and three (3) were males and their ages ranged between 5-11 months. Two (2) of the children that could not be followed up were older than 1 year - they were 5 and 8 years respectively.

\subsection{Discussion of Findings}

The findings will be discussed following the outline as portrayed in tables I, II, III.

\subsubsection{Complete Emollient Therapy}

Three categories were identified in this theme, namely: new information; amount of emollient prescribed and dispensed; and complete emollient therapy is effective, but it takes time.

Table 3. Complete emollient therapy

Prescribe the complete emollient ointment (not aqueous cream) as the first line of treatment for all children with atopic eczema

Provide sufficient quantities of emollient that is at least $250 \mathrm{~g} / \mathrm{week}$, depending on the severity and the size of the child. Bigger children could need more

Explain and demonstrate how to apply the emollient and how often (Provide pamphlet if available):

Apply the emollient at least twice daily over the whole body, and more often if needed, even if there are no symptoms

Shower or bath the child after swimming

The child should preferably bath once a day in warm water for a few minutes to hydrate the skin

After bathing the skin must be pat dried and not rubbed

Apply the emollient within three minutes after drying the child. Smooth it in as this improves the absorption and reduces the risk of developing occlusion folliculitis

Use the emollient as a stay on treatment as well as a soap and shampoo

Do not wash the hair while bathing

Emollient treatment often comes in a pot. To prevent bacterial contamination, the required amount must be scooped out with a clean spoon. Fingers should not come in contact with the content

The concept of complete emollient therapy, as explained in the guidelines (see table IV), was new information to all the PHC nurses and the parents. None of the PHC nurses knew what the difference was between aqueous cream and emulsifying ointment, before the training on $\mathrm{AE}$ and the guidelines. All of them used to prescribe aqueous cream as the stay on ointment and some prescribed emulsifying ointment to bath the child with. All the parents said that aqueous cream dried out the child's skin more and was very happy to receive emulsifying ointment as a first line treatment for the child's eczema.

"before I went to one of the lessons, remember the one that we did at the civic center, it was quite difficult, because I didn't know what to use.... then I learned about the, uh, emollient treatment, that really helped." (PHC nurse)

" ' $n$ ma het teruggekom na my en gesê sy het die complete emollient therapy begin toepas, tesame met al die ander goed wat sy in elk geval al doen, en dit is die eerste keer dat haar kind vir haar beter is" (A mother came back to me and said she used the complete emollient therapy, together with all the other things she was already doing, and this is the first time that her child seems to be better) (PHC nurse)

"So it was just getting everyone to adhere to the guidelines that was still challenging, because they still wanted to give the aqueous." (PHC nurse)

"So I used wipes and I used aqueous cream, because the Sister used aqueous cream so I thought, ah, the people all used aqueous cream" (Parent)

"I just bought another ointment and so on the dryness it was just, it was just dry, the skin was just dry... I like changed.... because that ointment if I use it, ja the skin will be a little bit soft at that time and then, uhm maybe 
some hours after you do, the skin will start peeling off like...So this happens like every day" (Parent) (Field note...the parent bought aqueous cream initially and the skin stayed dry, but after the change to the emulsifying ointment it became a bit more soft for some hours).

The use of complete emollient therapy seemed to work according to the participants. From the document analysis is was clear that the PHC nurses who agreed to participate in the research all prescribed and dispensed emulsifying ointment, but mostly one jar of $700 \mathrm{~g}$ at a time $(\mathrm{n}=10)$. The PHC nurses struggled to get larger amounts from the central pharmacy and therefore advised their parents to buy more if it runs out before their next clinic visit. The parents were happy with the emollient prescribed, but they found it was not enough to last for the whole month and they had to buy more from the pharmacy.

"I saw with most parents that, you know that with eczema the skin dries out very quickly, so we'll give them that big emulsifying ointment” (PHC nurse)

"what I usually advise my patients is, use especially those you can afford, because you know not everybody can, uh, the E45" (PHC nurse)

"at the clinic they gave me this one pot... Hmm, they say that I should buy" (PHC nurse)

All the participants reported that complete emollient therapy is effective, but is takes time to show results. Some of the parents lost hope if it did not work immediately and the PHC nurses reported they really had to spend time on explaining the importance of compliance, the chronic nature of $\mathrm{AE}$ and that the parents had to persevere with the treatment.

"die complete emollient therapy werk regtig, maar dit vat bietjie tyd en soos met alle chroniese toestande is die compliance belangrik" (the complete emollient therapy really works, but it takes time and as with all chronic conditions, compliance is important) (PHC nurse)

“Because I think they became negative as soon as they didn't see a result immediately. They thought that they'll see results immediately" (PHC nurse)

"But then after a week or so it became even more better. Ja so it became better as time goes by, but I had to continue with the therapy. So he doesn't work immediately, but after some time you start seeing really good results" (Parent)

One of the most common features of AE is a dry skin, with resultant itchiness, inflammation, disruption of the skin barrier and resultant change in the permeability and anti-microbial function of the skin (Cork et al., 2009). Various studies showed that emollients are an effective topical treatment and reduce the xerosis and pruritus and increase the eczema-free period (Cork et al, 2009; Giordario-Labadu, Cambazard, Guillet, Combemale \& Mengeaud, 2006; Wirén et al., 2009; Boralevi et al., 2013; Mason et al., 2013; Ăkerström et al., 2015). Complete emollient therapy can also be used as a stand-alone treatment in many pediatric patients (Sugarmann \& Parish, 2009). A recent study also indicated that complete emollient therapy from birth could be a valuable and cost effective strategy in prevention of AE (Simpson et al., 2014).

Various guidelines regarding AE support complete emollient therapy as the baseline for treating patients with AE (Moncrieff et al, 2013; Green \& Sinclair, 2014; Wollenberg et al., 2016).

\subsubsection{Topical Corticosteroid Therapy (TCS)}

Topical corticosteroids formed part of the drug treatment prescribed by all the PHC nurses and all the parents indicated that they received a tube of treatment to apply on the affected areas. According to the document analysis, all the patients received $1 \%$ hydro-corticosteroid ointment $(n=10)$ and only one patient was referred to the clinic doctor for a prescription of a moderate strength topical corticosteroid ointment $(n=1)$. According to the interviews, the $1 \%$ hydro-corticosteroid ointment was sometimes effective, but many patients got a stronger TCS from private doctors and felt it worked much better than the TCS received at the clinic. The finger-tip-unit guidelines to apply TCS was not recorded; only one of the parents alluded to it and 4 PHC nurses said that it helped them to know how much TCS to apply.

"she just gave me Mylocort and it wasn't working, so we had to go to a doctor. And the doctor prescribed Persivate mixed with aqueous cream, so it worked and then he told me if after a week it doesn't work, then I should go back to him, but it worked. And when I went to go collect it at the pharmacy, they told me don't use it. They told me not to use a lot of it, because apparently it......something with the skin.... But then I stopped using it and it came back and it was worse, so then I decided to just continue with it." (Parent)

"We don't have that uh-huh... the stronger cortisone. Ja, so I used to advise some of the parents to just go, so you 
need to go to a doctor... because you can't buy it, it's a schedule four I think. (PHC nurse)

"the fingertip and you ....That's very important also. We can also focus on that, because some now just wanted to use a lot of this lotion, the Mylocort." (PHC nurse)

"That fingertip thing is actually important, because as a mother you are stressing too much and you just want to apply more, thinking that you're helping the baby" (Parent)

Another leg of drug treatment for childhood AE is topical corticosteroid therapy. In a systematic review of randomised controlled trials, it was found that, although studies were of poor methodological quality, the outcomes reported showed strong positive treatment effects of topical corticosteroids (TCS) compared to placebos (Hoare, Li Wan Po \& Williams, 2000).

Different consensus groups, guideline development groups or health systems have developed guidelines for the management of AE (Green \& Sinclair, 2014; Eichenfield et al., 2015; Wollenberg et al., 2016; Haahtela, von Hertzen, Mäkelä, \& Hannuksela, 2008). These guidelines have different stepwise approaches to TCS treatment.

\subsubsection{Health Education}

The health education aspects covered in the shortened guideline for PHC nurses on the management of AE - those who were trained and took part in this pilot study - included: complete emollient therapy, topical treatment applications and compliance to treatment, environmental factors and dietary factors.

From the document analysis it was found that health education formed part of the consultations and was recorded in all the files $(n=10)$, although only three of these entries specified what the health education was about, namely discouraging the use of soaps $(n=1)$, complete emollient therapy $(n=1)$ and the use of soft clothing $(n=1)$. In the interviews, all the PHC nurses indicated that they gave health education to the parents. The parents also said they were taught on how to help their child with AE. The topics that were included in the health education - as identified from the interviews - were: aspects of complete emollient therapy; not to use soaps; which washing powder or stasoft for clothes to use; and the use of soft clothes and/or blankets.

"I use emulsifying, I apply emulsifying before I put her in the water, because I can't use soap and then I wash her, I wash it off, I wash the emulsifying ointment off. And after that I, uhm, I pat her dry and then I apply the mixture of Persivate and Epizone" (Parent)

"this one I use when the kid's bathing, I use it as a soap. So I don't use any soap, this is his soap. After that I apply it on the affected area. Also this one, the paraffin one, I apply it on the affected areas." (Parent)

"It makes like a nice little foam, so it also gives you the thing like, your baby is getting washed nicely and you, you feel safer, because you know that it's not soap, so it's not like corrosive to the skin or anything like that. And then they can use the emulsifying rather as a lotion." (PHC nurse)

"they also told me, to, to try and uhm, when she sleeps, she doesn't use blankets. So I put the sheet under the blanket, because the sheet is mos cotton. So they told me to try and cover her with cotton and with, uhm, or with silk. So even if she is wearing something like this, she is wearing a long sleeved cotton vest underneath" (Parent)

"No, he said something about clothing and, uhm, washing powders, said you must use only sunlight and you must buy cotton clothes only." (Parent)

"after washing her clothes I put softener on it you know. And they told me to stop with it, I think that also helped" (parent)

From the interviews with the parents it was clear that non-evidence based health education on food elimination was done, although it was not evident from the interviews with the PHC nurses nor from entries made in the patients' files.

"Yes, uhm, they told me to cut down on, on dairy products, because I love my cheese and I love my yoghurt. So they told me to cut back on it, even on milk, anything dairy product, because it could be the cause." (Parent)

"they said I should change the formula". (Parent)

The need for more health education was also an aspect that was clear from the interviews, but there was often not enough time to give more health education (PHC nurse) or to ask questions (parents).

"So the guidelines they helped a lot and it also helps you also to find what could also be the cause of this, because then you probe further, that's when you realize that that's when she's also doing something wrong." (PHC nurse)

"Yeah, that is a lot. I want to know, this, what does, what cause this disease, exactly, because I don't really know what happened? Then if I know the causes, then I can be able to ask some questions that I want to know. I didn't 
have a chance to ask.... The thing is the nurse was questioning me a lot." (Parent)

The interviews indicated that compliance to both drug and health education (non-drug) treatment is important and that parents need to be patient and persevere with the treatment as AE takes time to get better and can re-occur.

"I'm really happy about it...emollient therapy as much as it sounds like it's not much and when it comes to the lifestyle changes, it really, really makes a big difference. Because I saw it with the patients. "(PHC nurse)

"....and another thing is that patience, like we, we must also educate the mothers and everyone, just not to expect immediate results. Yeah, it doesn't work immediately. So you need to have patience." (PHC nurse)

"But then as time continued on, it started to, to go away and then became more and more, now only left this side only. So it took some time actually to be here." (Parent)

Allergy experts are in consensus that educational interventions should form part of the management of $\mathrm{AE}$ and that time spent on the educational intervention is an important factor which impacts on the success or not of educating the parents (SIGN, 2011; Stalder et al., 2013; Moore, Williams, Manias, Varigos, 2006; Sinclair, Green \& Levin, 2014; Ersser et al., 2014; Wollenberg et al., 2016).

It was clear from the findings that health education on complete emollient therapy and the compliance to treatment were included in the management of the children with AE who were part of this pilot study. Aspects on environmental factors did not really feature in the findings, and some non-evidence based health education on dietary factors were alluded to by the parents.

\subsubsection{Lack of Using Guidelines}

The findings from the documentation and interviews showed that some areas of the guidelines were lacking.

No entrances were found in the patients' files on the severity of the AE as mild, moderate or severe eczema $(n=0)$. Two PHC nurses indicated in the interviews that they had more knowledge now on how to determine the severity of the $\mathrm{AE}$, but it was not clear whether this knowledge was acted on to help them decide on the treatment.

"at first I didn't realize the difference between mild, moderate and severe eczema. But as I continued using the guidelines then I could see that this one it's severe" (PHC nurse)

In the latest South African guideline for atopic dermatitis (Sinclair, Green \& Levin, 2014) a simplified way to assess the severity of the $\mathrm{AE}$ is given. In order to align the PHC guidelines for childhood $\mathrm{AE}$ to the guideline for medical practitioners, similar severity assessments were applied and appears in Table V. This formed part of the guidelines and the training session for the PHC nurses.

Table 4. Severity of atopic eczema

Mild:

- $\quad<5 \%$ body surface involved

- No acute changes

- No significant impact on quality of life
Moderate:
- $<30 \%$ body surface involved
- Mild dermatitis with acute changes
- Mild dermatitis with significant impact on quality of life

Severe:

- $>30 \%$ body surface involved

- Moderate dermatitis with acute changes

- Moderate dermatitis with significant impact on quality of life

During document analysis, no entrance on referring a patient to another member of the multi-disciplinary team was found in the patients file and no PHC nurse or parent mentioned such a referral in the interviews. This lack might link to the fact that the severity of the AE was not clearly identified. There was also just one entry in a patient's file on referring the patient to the clinic doctor for a stronger TCS $(n=1)$. However, some parents used a stronger TCS 
that they got from a private doctor.

"It's an ointment the Advantan ointment, Advantan cream. I bought that from one of the other... it was a doctor." (Parent)

In a systematic review and meta-analysis done on psychological and educational interventions for AE in children, it was concluded that studies were not comparable; however, there were indications that a multidisciplinary approach can improve the severity of the disease as well as the quality of life of the child and family. More research is needed to determine who would be the most suitable disciplines to form part of such a team (Ersser et al, 2014; LeBovidge et al., 2016)

There was one entrance found in the patients' file indicating the prescription of an H1-receptor anti-histamine $(\mathrm{n}=1)$, but the reason for the prescription was not clear. One PHC nurse said in the interview a challenge experienced was that anti-histamine is often given with no indication for it.

"But again the challenge was still getting some of the old nurses to also know that, no this is how we treat it now. You don't have to give this, you know, you don't have to give Allergex unless it's really severe or whatever." (PHC nurse)

In a systematic review done in 2013, there was a lack of evidence on the effectiveness of oral H1 antihistamine as a monotherapy has on AE; it was however, concluded that it could be used as an add-on therapy for AE due to the sedative effects it has (Apfelbacher et al., 2013). The South African consensus document for childhood AE states that a sedative antihistamine could be used before bedtime (Manjra et al., 2005) but this was not included in the South African management guideline for childhood AE (Puterman, Lewis, Sinclair \& Green, 2014). However, a study on parental perception of the role of antihistamine in the management of $\mathrm{AE}$ in their children, found that parents valued antihistamine equal to that of TCS in managing their children AE (Chawla et al., 2016) and from the findings of this research is seems that PHC nurses might have the same perception, however more research is needed.

\section{Conclusion}

It became clear from the findings of this pilot study, that the primary health management guidelines for childhood $\mathrm{AE}$, were only partially followed by the PHC nurses. This was despite the fact that a shortened easy-to-use version was also provided to the nurses. The PHC nurses, who consented to partake in the research, found some elements of the guidelines as very helpful, especially the complete emollient therapy and evidence based health education. The reasons given by the trained PHC nurses who did not consent to participate in the research, indicated that they either were not interested in the topic or did not have the time to try new interventions.

The findings of this research showed that a new intervention, especially for conditions that are not viewed by many PHC nurses as very important, must be really easy to use. As a way forward, it will be more effective to enhance the knowledge of PHC nurses on basic elements of AE care that will have a definite impact on the condition and the quality of life of the child affected. From the findings of this pilot study it seemed that the complete emollient skin care made the biggest difference, together with the knowledge of the TCS and the amount to apply. Evidence health education was also deemed as being useful to the PHC nurse and parent. Therefore, these aspects would be included in a basic guide for PHC nurses to treat AE. The broader aspects contained in the complete guideline could in future form part of a short course on AE for PHC nurses.

\subsection{Limitations of the Study}

The number of consenting PHC nurse participants were small despite the fact that a fair number of PHC nurses were trained. The parents interviewed all had children less than one (1) year of age, and the voice and experience of parents with older children were not heard. Very cryptic recording in patients' files resulted in limited value for data analysis. Due to the pilot study, the numbers of the population used is small.

\section{Competing Interests Statement}

A research grant from ALLSA/CIPLA made the research possible.

\section{References}

Akdis, C. A., Akdis, M., Bieber, T., Bindslev-Jensen, C., Boguniewicz, M., Eigenmann, P., ... \& Luger, T. A. (2006). Diagnosis and treatment of atopic dermatitis in children and adults: European Academy of Allergology and Clinical Immunology/American Academy of Allergy, Asthma and $\begin{array}{llll}\text { Immunology/PRACTALL Consensus } \quad \text { Report. } & \text { Allergy, } & \text { 61(8), }\end{array}$ https://doi.org/10.1111/j.1398-9995.2006.01153.x 
Ăkerström, U., Reitamo, S., Langeland, T., Berg, M., Rustad, L., Korhonen, L., ... Svensson. (2015). Atopic dermatitis relaps: A randomized double-blind controlled multicenter clinical trial. Acta-Dermato-Venereologica, 95(5), 587-592. https://doi.org/10.2340/00015555-2051

Apfelbacher, C. J., van Zuuren, E. J., Fedorowicz, Z., Jupiter, A., Matterne, U., \& Weisshaar, E. (2013). Oral H1 antihistamines as monotherapy for eczema. Cochrane Database of Systematic Reviews, (2). https://doi.org/10.1002/14651858.CD007770.pub2

Boralevi, F., Saint Aroman, M., Delarue, A., Raudsepp, H., Kaszuba, A., Bylaite, M., \& Tiplica, G. S. (2014). Long-term emollient therapy improves xerosis in children with atopic dermatitis. Journal of the European Academy of Dermatology and Venereology, 28(11), 1456-1462. https://doi.org/10.1111/jdv.12314

Brouwers, M. C., Kho, M. E., Browman, G. P., Burgers, J. S., Cluzeau, F., Feder, G., ... \& Littlejohns, P. (2010). AGREE II: advancing guideline development, reporting and evaluation in health care. Cmaj, 182(18), E839-E842. https://doi.org/10.1503/cmaj.090449

Chawla, V., Hogan, M. B., Moonie, S., Fenwick, G. L., Hooft, A., \& Wilson, N. W. (2016, March). Parental perception of efficacy of antihistamines for pruritus in pediatric atopic dermatitis. In Allergy \& Asthma Proceedings (Vol. 37, No. 2). https://doi.org/10.2500/aap.2016.37.3927

Cork, M. J., Danby, S., Vasilopoulos, Y., Moustafa, M., MacGowan, A., Varghese, J., ... \& Ward, S. J. (2008). Epidermal barrier dysfunction in atopic dermatitis. In Textbook of Atopic Dermatitis (pp. 47-70). CRC Press. https://doi.org/10.1038/jid.2009.133

Cox, H., Lloyd, K., Williams, H., Arkwright, P. D., Brown, T., Clark, C., ... \& Lewis-Jones, S. (2011). Emollients, education and quality of life: the RCPCH care pathway for children with eczema. Archives of disease in childhood, 96(Suppl 2), i19-i24. https://doi.org/10.1136/archdischild-2011-300695

Creswell, J. (2014). Research design: Qualitative, quantitative and mixed methods approaches. Los Angeles: Sage.

McQuoid-Mason, D., \& Dhai, A. (2011). Bioethics, Human Rights and Health Law: Principles and Practice.

Eichenfield, L. F., Boguniewicz, M., Simpson, E. L., Russell, J. J., Block, J. K., Feldman, S. R., ... \& Paller, A. S. (2015). Translating atopic dermatitis management guidelines into practice for primary care providers. Pediatrics, 136(3), 554-565. https://doi.org/10.1542/peds.2014-3678

Ersser, S. J., Cowdell, F., Latter, S., Gardiner, E., Flohr, C., Thompson, A. R., ... \& Drury, A. (2014). Psychological and educational interventions for atopic eczema in children. Cochrane Database of Systematic Reviews, (1). https://doi.org/10.1002/14651858.CD004054.pub3

Gauteng department of health. (n.d). Gauteng Clinics. Retrieved from http://www.healthgpg.gov.za/Pages?Gauteng-Clinics.aspx

Giordano-Labadie, F., Cambazard, F., Guillet, G., Combemale, P., \& Mengeaud, V. (2006). Evaluation of a new moisturizer (Exomega milk ${ }^{\circledR}$ ) in children with atopic dermatitis. Journal of dermatological treatment, 17(2), 78-81. https://doi.org/10.1080/09546630600552216

Green, R. J. (2014). Summary: General approach to and summary of the guideline for the management of atopic dermatitis. South African medical Journal, 104(10), 720-721. https://doi.org/10.7196/SAMJ.8876

Guetterman, T. C., Fetters, M. D., \& Creswell, J. W. (2015). Integrating quantitative and qualitative results in health science mixed methods research through joint displays. The Annals of Family Medicine, 13(6), 554-561. https://doi.org/10.1370/afm. 1865

Haahtela, T., Von Hertzen, L., Mäkelä, M., Hannuksela, M., \& Allergy Programme Working Group. (2008). Finnish Allergy Programme 2008-2018-time to act and change the course. Allergy, 63(6), 634-645. https://doi.org/10.1111/j.1398-9995.2008.01712.x

Hoare, C., Po, A. L. W., \& Williams, H. (2000). Systematic review of treatments for atopic eczema. Health technology assessment (Winchester, England), 4(37), 1. https://doi.org/10.3310/hta4370

LeBovidge, J. S., Elverson, W., Timmons, K. G., Hawryluk, E. B., Rea, C., Lee, M., \& Schneider, L. C. (2016). Multidisciplinary interventions in the management of atopic dermatitis. Journal of Allergy and Clinical Immunology, 138(2), 325-334. https://doi.org/10.1016/j.jaci.2016.04.003

Licoln, Y. S., \& Guba, E. G. (1985). Naturalistic Inquiry. Newbury Park: Sage.

Manjra, A. I., Du Plessis, P., Weiss, R., Motala, C. M., Potter, P. C., Raboobee, N., ... \& Weinberg, E. G. (2005). 
Childhood atopic eczema consensus document. South African Medical Journal, 95(6).

Mason, J. M., Carr, J., Buckley, C., Hewitt, S., Berry, P., Taylor, J., \& Cork, M. J. (2013). Improved emollient use reduces atopic eczema symptoms and is cost neutral in infants: before-and-after evaluation of a multifaceted educational support programme. BMC dermatology, 13(1), 7. https://doi.org/10.1186/1471-5945-13-7

Meintjes, K. F. (2016). Primary health care management guidelines for childhood atopic eczema (Doctoral dissertation, University of Johannesburg).

Moncrieff, G., Cork, M., Lawton, S., Kokiet, S., Daly, C., \& Clark, C. (2013). Use of emollients in dry-skin conditions: consensus statement. Clinical and experimental dermatology, 38(3), 231-238. https://doi.org/10.1111/ced.12104

Moore, E., Williams, A., Manias, E., \& Varigos, G. (2006). Nurse-led clinics reduce severity of childhood atopic eczema: a review of the literature. British Journal of Dermatology, 155(6), 1242-1248. https://doi.org/10.1111/j.1365-2133.2006.07534.x

Polit, D. F., \& Beck, C. T. (2012). Nursing research: generating and assessing evidence for nursing practice (9th ed.). Philadelphia: Wolters Kluwer/Lippincott Williams \& Wilkins.

Puterman, A., \& Green, R. J. (2014). Topical and systemic pharmacological treatment of atopic dermatitis. South African Medical Journal, 104(10), 716-719. https://doi.org/10.7196/SAMJ.8870

Scottish Intercollegiate Guidelines Network (SIGN). Management of atopic eczema in primary care. [https://www.sign.ac.uk/sign-125-management-of-atopic-eczema-in-primary-care.html ] [updated March 2011; cited 13 May 2019]. Available from: https:/www.sign.ac.uk/sign-125-management-of-atopic-eczema-in-primary-care.html

Simpson, E. L., Chalmers, J. R., Hanifin, J. M., Thomas, K. S., Cork, M. J., McLean, W. I., ... \& Williams, H. C. (2014). Emollient enhancement of the skin barrier from birth offers effective atopic dermatitis prevention. Journal of Allergy and Clinical Immunology, 134(4), 818-823. https://doi.org/10.1016/j.jaci.2014.08.005

Sinclair, W., Aboobaker, J., Green, R. J., \& Levin, M. E. (2014). Diagnosis of atopic dermatitis: From bedside to laboratory. SAMJ: South African Medical Journal, 104(10), 711-713. https://doi.org/10.7196/SAMJ.8850

Stalder, J. F., Bernier, C., Ball, A., De Raeve, L., Gieler, U., Deleuran, M., ... \& Gelmetti, C. (2013). Therapeutic patient education in atopic dermatitis: worldwide experiences. Pediatric dermatology, 30(3), 329-334. https://doi.org/10.1111/pde.12024

Sugarman, J. L., \& Parish, L. C. (2009). Efficacy of a lipid-based barrier repair formulation in moderate-to-severe pediatric atopic dermatitis. Journal of drugs in dermatology: JDD, 8(12), 1106-1111.

Wiren, K., Nohlgård, C., Nyberg, F., Holm, L., Svensson, M., Johannesson, A., ... \& Lodén, M. (2009). Treatment with a barrier-strengthening moisturizing cream delays relapse of atopic dermatitis: a prospective and randomized controlled clinical trial. Journal of the European Academy of Dermatology and Venereology, 23(11), 1267-1272. https://doi.org/10.1111/j.1468-3083.2009.03303.x

Wollenberg, A., Oranje, A., Deleuran, M., Simon, D., Szalai, Z., Kunz, B., ... \& de Bruin-Weller, M. (2016). ETFAD/EADV Eczema task force 2015 position paper on diagnosis and treatment of atopic dermatitis in adult and paediatric patients. Journal of the European Academy of Dermatology and Venereology, 30(5), 729-747. https://doi.org/10.1111/jdv.13599

\section{Copyrights}

Copyright for this article is retained by the author(s), with first publication rights granted to the journal.

This is an open-access article distributed under the terms and conditions of the Creative Commons Attribution license (http://creativecommons.org/licenses/by/4.0/). 